\title{
An unusual complex suicide by corrosive ingestion and stabbing
}

\author{
Kamil Hakan Dogan ${ }^{1}$, Serafettin Demirci ${ }^{2}$, I dris Deniz ${ }^{2}$ \\ 1. Department of Forensic Medicine, Faculty of Medicine, Selcuk University, Konya, Turkey. 2. Department of Forensic \\ Medicine, Meram Medical School, Necmettin Erbakan University, Konya, Turkey
}

Correspondence: Kamil Hakan Dogan, MD, PhD, Assoc. Professor of Forensic Medicine. Address: Department of Forensic Medicine, Faculty of Medicine, Selcuk University, Konya, Turkey. Email: drhakan2000@gmail.com

Received: January 10, 2014

Accepted: February 12, $2014 \quad$ Online Published: February 18, 2014

DOI : $10.5430 /$ crcp.v1n1p8

URL: http://dx.doi.org/10.5430/crcp.v1n1p8

\section{Abstract}

Suicides are divided into simple and complex, the complex one referring to suicide by a combination of more than one method. In general, unplanned complex suicides occur where several different methods are used consecutively because the first method has not achieved the desired effect.

In this study, we present a unique unplanned complex suicide case where corrosive ingestion and stabbing were the suicide methods.

A 50-year-old woman was found unconscious by her husband and daughter in the garden of her house in the middle of the night. She was transported to the hospital, where she was pronounced dead upon arrival. The investigation revealed that there was a half-filled bottle of scale dissolver containing nitric acid in the kitchen of the house. The deceased was said to have been suffering from depression for two weeks. There were corrosive burns around the lips, on the chin and on the right side of the neck, three stab wounds and six tentative cuts above the umbilical region.

This is the first case report of unplanned complex suicide by corrosive ingestion and stabbing in the literature. It is thought that the woman first swallowed nitric acid, and after feeling unbearable pain around her epigastric region, she stabbed herself in the abdomen. A brief discussion about the methods used in this case and an overview of the complex suicide entity is presented.

\section{Key words}

Suicide, Complex, Stabbing, Corrosive, Death

\section{I ntroduction}

Complex suicides can be defined as the use of more than one method to induce death ${ }^{[1-5]}$. In 1974, Marcinkowski et al. ${ }^{[5]}$ had proposed a general division of suicide. In this classification, suicides are first divided into simple versus complex, the complex type referring to suicide by a combination of methods. If the combination of multiple suicidal methods is previously planned, the suicide is categorized as "planned", while if the failure of the first mechanism brings the victim to come up with an alternative method of inflicting death, it is categorized as "unplanned" ${ }^{[1,6,7]}$. 
In this study, a unique unplanned complex suicide case is presented where corrosive ingestion and stabbing were the suicide methods.

\section{Case report}

A 50-year-old woman was found unconscious by her husband and daughter in the garden of her house in the middle of the night. She was transported to the hospital, where she was pronounced dead upon arrival. The investigation revealed that there was a half-filled bottle of scale dissolver containing nitric acid in the kitchen of the house. According to her husband, she had been suffering from depression for two weeks.

At external examination, there were corrosive burns around the lips, on the chin and on the right side of the neck (see Figure 1). Three parallel stab wounds each $2 \mathrm{~cm} \times 0.5 \mathrm{~cm}$ in diameter and six superficial self-inflicted tentative cuts above the umbilical region were observed (see Figure 2).

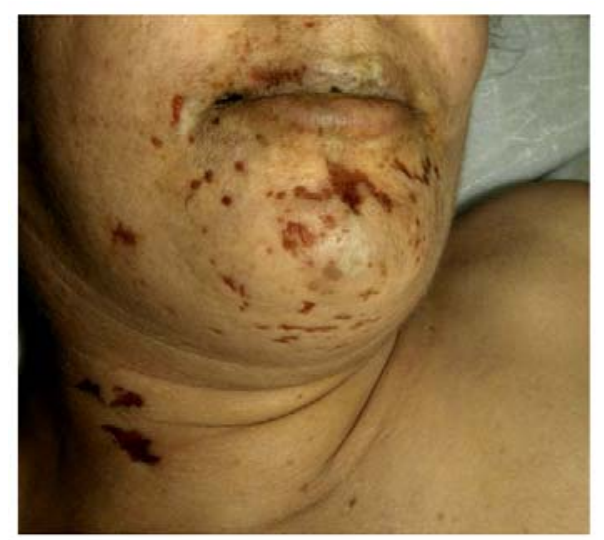

Figure 1. Corrosive burns around the lips, on the chin and on the right side of the neck.

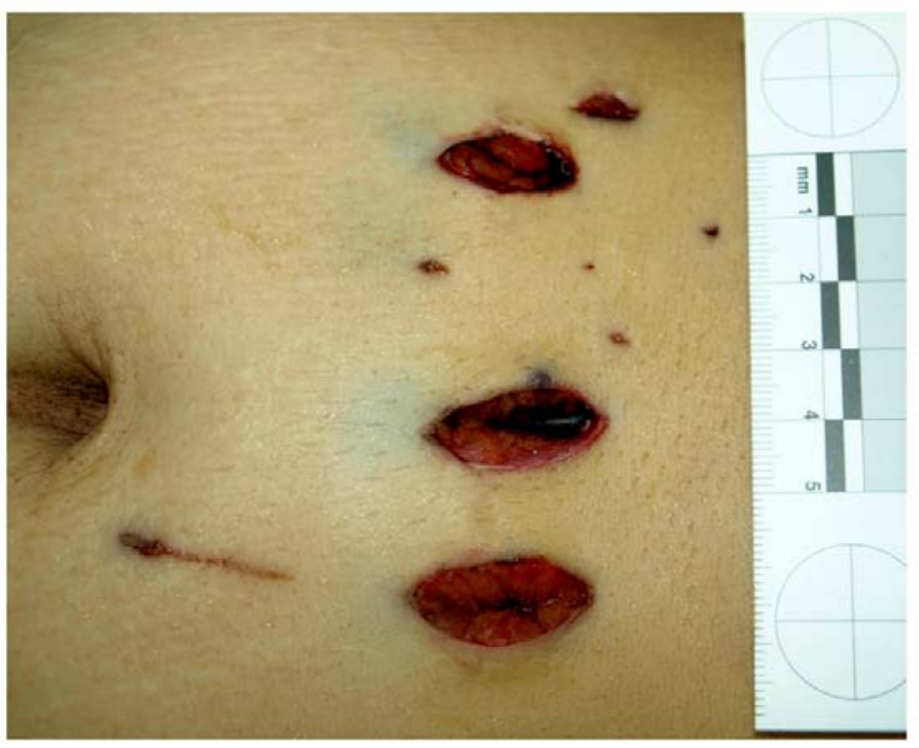

Figure 2. Stab wounds and superficial self-inflicted tentative cuts above the umbilical region. 
At internal examination, approximately $200 \mathrm{ml}$ of blackish-red (sero-hemorrhagic) fluid was found in peritoneal cavity (see Figure 3). The mucosal surface of the tongue and oropharynx showed yellowish-green discoloration due to denaturation. The mucosa of the esophagus, trachea and stomach demonstrated a yellowish-green discoloration and areas of extensive full-thickness necrosis (see Figure 4). The esophagus and stomach were slimy and softened. There was a single perforation measuring $3 \mathrm{~cm} \times 3 \mathrm{~cm}$ in the prepyloric region of the stomach. Three stab wounds penetrated the peritoneum, and they only cut the omentum. All of the internal organs were congested. According to autopsy findings, it was concluded that the cause of death was internal organ injury and chemical peritonitis due to ingestion of nitric acid.

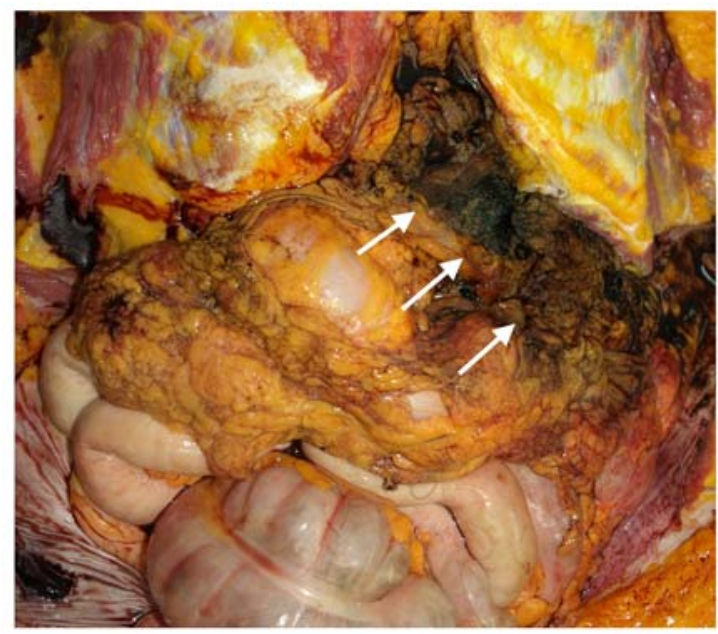

Figure 3. Blackish-red (sero-hemorrhagic) fluid in the peritoneal cavity due to perforated stomach.

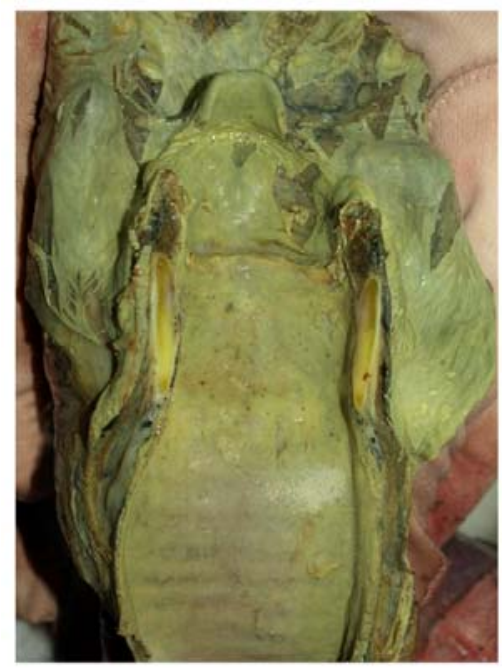

Figure 4. Yellowish-green discoloration of the mucosa of the esophagus and trachea.

\section{Discussion}

Chemical burn injuries constitute a type of burn injury that we may come across in our daily practice, although not as frequently as thermal and electric injuries. Acids such as sulfuric acid, nitric acid, hydrochloric acid, tannic acid and formic acid are widely used and handled by many individuals ${ }^{[8]}$. 
Nitric acid (NHO3), also known as aqua fortis (“strong water”) or spirit of nitre or engraver's acid, is a chemical important for industrial and domestic purposes. It is a strong oxidizing agent that ionizes readily and is a highly electrically conductive solution. Being a corrosive, it produces immediate pain and causes burns of the mouth, throat, esophagus and intra-abdominal organs. Forty-five percent solutions of $\mathrm{NHO}_{3}$ are commonly used as a cleaner and scale dissolver in Turkey ${ }^{[8-10]}$.

The pathophysiology depends on the type of the acid, its $\mathrm{pH}$, its molar concentration, the volume ingested, duration of contact, the presence of other contents in the stomach and the gastric emptying time of the acids concerned. Esophageal injury occurs in 6\%-20\% of acid ingestion. Esophageal injury is mild, as there is a rapid transit and limited permeability, hence less chances of perforation, which will always be associated with gastric damage ${ }^{[9]}$. Acids cause coagulation necrosis of the tissues with thrombus formation in the microvasculature of the lesion. In high concentration and volume, nitric acid reacts with blood, forming acid hematin, which causes charring (black discoloration) ${ }^{[8]}$. There were mild esophageal injury, gastric perforation and black-colored fluid in the peritoneal cavity due to gastric perforation in our case.

There are three reports of complex suicides concerning acid ingestion in the literature. Faller-Marquardt et al. ${ }^{[11]}$ reported three emigrants (one man, two women) who drank acetic acid before hanging themselves. Canale ${ }^{[12]}$ reported a man who used three methods: wrist cutting, ingestion of hydrochloric acid and "traffic accident" with a car. Altun ${ }^{[13]}$ reported a man who had taken some antidepressant and antipsychotic drugs before cutting his right wrist and ingesting a large amount of concentrated hydrochloric acid. The present study is the first known report of a complex suicide case in which nitric acid ingestion was used as one of the suicide methods and that involved unplanned complex suicide by corrosive ingestion and stabbing.

In every case with fatal sharp-weapon injuries, differentiation between suicide and homicide is always required. The classical criteria for discriminating suicide by self-cutting or -stabbing from homicide are generally considered as follows: (a) several injuries are observed on the possible sites of self-infliction; (b) hesitation marks are present; (c) clothing tears are absent ${ }^{[14]}$. There were several stab wounds and hesitation marks on the abdomen of the woman, and there were not any clothing tears in the presented case.

The term "complex suicide" does not denote the resourcefulness or intricacy of the suicide method but rather specifies the use of more than one type of suicide method. Complex suicide can be divided into two distinct groups: planned and unplanned complex suicides (other terms have been coined, such as primary combined (planned complex) and secondary combined) ${ }^{[15]}$. In the forensic literature, complex suicides have been reported to account for about $1.5 \%-5.0 \%$ of all suicides ${ }^{[1,2]}$.

In planned complex suicides, two or more suicide methods are applied simultaneously to guarantee and/or accelerate death or avoid pain. The methods used reflect the whole spectrum seen in "simple" suicides ${ }^{[2,5,13,16-18]}$.

In unplanned complex suicides, one or more other methods of suicide are tried after the first method fails to gain one's end or when it proves too painful ${ }^{[2,3]}$. In fact, unplanned complex suicides do not represent a combined use or a planned combination of several methods, but rather they reflect a switch to another suicide method after the first. If the first method fails, turns out to be unexpectedly painful or does not cause death quickly enough, another mode may be chosen provided that the individual is still conscious and able to act. The choice of a second or third method is mainly determined by the availability of means in the concrete situation (e.g., jumping from a height when living on an upper floor) ${ }^{[2,19]}$. It is thought that the woman in this case first swallowed nitric acid, and after feeling unbearable pain around her epigastric region, she stabbed herself in the abdomen.

In most suicides, the victim first inflicts superficial cuts and/or stabs before he or she switches to an effective method, such as hanging, shooting or jumping from a height ${ }^{[11,15,20-22]}$. The woman in the presented case is different from any 
previously reported cases, as the stab wounds were inflicted as a second method after the fatal corrosive ingestion. Additionally, the stab wounds were not superficial, as they reached the peritoneal cavity.

The forensic pathologist performing the autopsy in unplanned suicide cases will also have to answer questions regarding the chronological order of the injuries as well as how long and to what extent the suicidal individual was able to act after he or she sustained the injuries ${ }^{[2]}$. As the woman in our case stabbed herself after feeling unbearable pain around her epigastric region, it is appropriate to classify this case as an unplanned complex suicide.

From the criminological point of view, the presence of several different injuries on a deceased individual is especially suspicious as indicating homicide. Careful inspection of the death scene, a thorough investigation of the surroundings of the deceased and a full autopsy are necessary to elucidate the correct mode of death in such cases. The chronological order of the methods applied can be reconstructed only if all information available on the given case is taken into consideration. Apart from the outcome of the autopsy, all traces found at the death scene, as well as the statements of witnesses concerning the sequence of events, if available, are of particular importance in this context. Solely based on autopsy findings, a sufficient reconstruction is rarely possible (i.e., in such cases in which there are only two injuries and one of them was nonfatal) ${ }^{[2]}$. Although a scene investigation was not performed in our case, autopsy findings and the statements of the witnesses were enough to determine the chronological order of the methods applied.

\section{References}

[1] Racette S, Sauvageau A. Planned and unplanned complex suicides: a 5-year retrospective study. J Forensic Sci. 2007 ; 52: 449-452. http://dx.doi.org/10.1111/j.1556-4029.2007.00387.x

[2] Bohnert M. Complex suicides. In: Tsokos M, ed. Forensic Pathology Reviews. Vol 2. Totowa, NJ: Humana Press Inc. 2005: 127143. http://dx.doi.org/10.1385/1-59259-872-2:127

[3] Taff ML, Boglioli LR, Danto BL. Planned complex suicide. Am J Forensic Med Pathol. 1998; $19: 194$. http://dx.doi.org/10.1097/00000433-199806000-00020

[4] Cingolani M, Tsakri D. Planned complex suicide: report of three cases. Am J Forensic Med Pathol. 2000; 21: 255-260. http://dx.doi.org/10.1097/00000433-200009000-00015

[5] Marcinkowski T, Pukacka-Sokolowska L, Wojciechowski T. Planned complex suicide. Forensic Sci. 1974; 3: 95-100. http://dx.doi.org/10.1016/0300-9432(74)90013-2

[6] Viel G, Schröder AS, Püschel K, Braun C. Planned complex suicide by penetrating captive-bolt gunshot and hanging: case study and review of the literature. Forensic Sci Int. 2009; 187(1-3): e7-11. http://dx.doi.org/10.1016/j.forsciint.2009.01.022

[7] Bohnert M, Rothschild MA. Complex suicides by self-incineration. Forensic Sci Int. 2003; 131: 197-201. http://dx.doi.org/10.1016/S0379-0738(02)00449-8

[8] Shetty BS, Shetty M, Raj Kumar K, Shrinidhi, Ullal H. An unusual circumstance of internal chemical burn injury - a case report. J Forensic Leg Med. 2008; 15(7): 450-453. http://dx.doi.org/10.1016/j.jflm.2008.01.007

[9] Ellenhorn MJ. Household Poisonings. In: Ellenhorn MJ, Schonwald S, Ordog G, Wasserberger J, eds. Ellenhorn’s Medical Toxicology: Diagnosis and Treatment of Human Poisoning. 2nd ed. Baltimore: Williams \& Wilkins; 1997. p. $1078-1123$.

[10] Eray O, Eken C, Oktay C, Gelen T, Avci AB. Comparison of systemic and local effects of nitric acid and hydrochloric acid: an experimental study in a rat model. Ulus Travma Acil Cerrahi Derg. 2006 Jul; 12(3): 184-188.

[11] Faller-Marquardt M, Bohnert M, Logemann E, Pollak S. Combined suicide by drinking acetic acid with subsequent hanging. Arch Kriminol. 2000; 206(5-6): 140-149.

[12] Canale M. L’ impiego dell' automobile come mezzo suicidario; considerazioni su un caso singolare di suicidio combinato. Zbl Rechtsmed. 1971; 2: 348.

[13] Altun G. Planned complex suicide: report of three cases. Forensic Sci Int. 2006; 157: 83-86. http://dx.doi.org/10.1016/j.forsciint.2005.04.039

[14] Ohshima T, Kondo T. Eight cases of suicide by self-cutting or -stabbing: consideration from medico-legal viewpoints of differentiation between suicide and homicide. J Clin Forensic Med. 1997; 4(3): 127-132. http://dx.doi.org/10.1016/S1353-1131(97)90092-4

[15] Palmiere C, Risso E, van Hecke O, La Harpe R. Unplanned complex suicide by self-strangulation associated with multiple sharp force injuries: a case report. Med Sci Law. 2007; 47(3): 269-273. http://dx.doi.org/10.1258/rsmmsl.47.3.269 
[16] Parra MW, Lube MW, Al-Khayat H, Cheatham ML. A planned complex suicide: need for a high index of suspicion. Am Surg. 2006; 72(5): 454-455.

[17] Padosch SA, Schmidt PH, Madea B. Planned complex suicide by selfpoisoning and a manipulated blank revolver: remarkable findings due to multiple gunshot wounds and self-made wooden projectiles. J Forensic Sci. 2003; 48: 1371-1378.

[18] Blanco-Pampin JM, Suarez-Penaranda JM, Rico-Boquete R, Concheiro-Carro L. Planned complex suicide: an unusual suicide by hanging and gunshot. Am J Forensic Med Pathol. 1997; 18: 104-106. http://dx.doi.org/10.1097/00000433-199703000-00020

[19] Töro K, Pollak S. Complex suicide versus complicated suicide. Forensic Sci Int. 2009; 184(1-3): 6-9. http://dx.doi.org/10.1016/j.forsciint.2008.10.020

[20] Demirci S, Dogan KH, Erkol Z, Deniz I. A series of complex suicide. Am J Forensic Med Pathol. 2009; 30(2): $152-154$. http://dx.doi.org/10.1097/PAF.0b013e318187deb7

[21] Nadjem H, Weinmann W, Pollak S. Ingestion of pointed objects in a complex suicide. Forensic Sci Int. 2007; 171(1): e11-14. http://dx.doi.org/10.1016/j.forsciint.2007.05.002

[22] Türk EE, Tsokos M. Vehicle-assisted suicide resulting in complete decapitation. Am J Forensic Med Pathol. 2005; $26(3)$ : $292-293$. http://dx.doi.org/10.1097/01.paf.0000176284.89468.68 